\title{
Vacuum grasping as a manipulation technique for minimally invasive surgery
}

\author{
D. Vonck • R. H. M. Goossens $\cdot$ D. J. van Eijk • \\ I. H. J. T. de Hingh $\cdot$ J. J. Jakimowicz
}

Received: 8 September 2009/Accepted: 3 February 2010/Published online: 2 March 2010

(C) The Author(s) 2010. This article is published with open access at Springerlink.com

\begin{abstract}
Background Laparoscopic surgery requires specially designed instruments. Bowel tissue damage is considered one of the most serious forms of lesion, specifically perforation of the bowel.

Methods An experimental setting was used to manipulate healthy pig bowel tissue via two vacuum instruments. During the experiments, two simple manipulations were performed for both prototypes by two experienced surgeons. Each manipulation was repeated 20 times for each prototype at a vacuum level of $60 \mathrm{kPa}$ and 20 times for each prototype at a vacuum level of $20 \mathrm{kPa}$. All the manipulations were macroscopically assessed by two experienced surgeons in terms of damage to the bowel.

Results In 160 observations, 63 ecchymoses were observed. All 63 ecchymoses were classified as not relevant and negligible. No serosa or seromuscular damages and no perforations were observed.

Conclusion Vacuum instruments such as the tested prototypes have the potential to be used as grasper instruments in minimally invasive surgery.
\end{abstract}

Keywords Minimally invasive surgery .

Nonconsequential tissue damage - Preset gripping forces .

Skill independent

D. Vonck $(\bowtie) \cdot$ R. H. M. Goossens · D. J. van Eijk ·

J. J. Jakimowicz

Faculty of Industrial Design Engineering, Department

of Applied Ergonomics and Design, Delft University

of Technology, Delft, The Netherlands

e-mail: d.vonck@tudelft.nl

I. H. J. T. de Hingh · J. J. Jakimowicz

Department of Surgery, Catharina Hospital, Eindhoven,

The Netherlands
Laparoscopic surgery requires specially designed instruments for manipulation of the internal organs in a safe manner [1-17]. Bowel tissue damage is considered one of the most serious forms of lesions [1, 18-20], and perforation of the bowel causes peritonitis, which leads to high rates of morbidity and mortality [18]. It also is possible to damage the tissue without immediate perforation. This may lead to local tissue necrosis, causing a delayed perforation of the bowel and resulting in serious complications for the patient [18, 21-23].

In industrial applications, vacuum is a common and successful grasping technique, especially when accuracy and delicacy are required. Some studies also show that vacuum technique can be used as a safe stabilizing and positioning technique during a surgical procedure [24-27]. In a joint project, Karl Storz and Delft University of Technology developed two vacuum technique-based grasper prototypes (patent no. NL2000796).

This study aimed to introduce a vacuum technique for laparoscopic bowel manipulation by testing the two vacuum grasper prototypes for bowel damage. In addition, the performance of the prototypes was explored in terms of tissue damage to the liver, the spleen, and the gallbladder.

\section{Materials and methods}

An experimental setting was used to manipulate healthy pig bowel tissue by means of two vacuum instruments (prototypes A and B; Figs. 1 and 2). The prototypes were constructed on the same technical principle and constructed such that both prototypes fit through a $12-\mathrm{mm}$ trocar (patent no. NL2000796).

Both prototypes were connected to a vacuum pump (Leybold, Germany). The vacuum pump generated a preset 
Fig. 1 Prototypes A (left) and B (right)
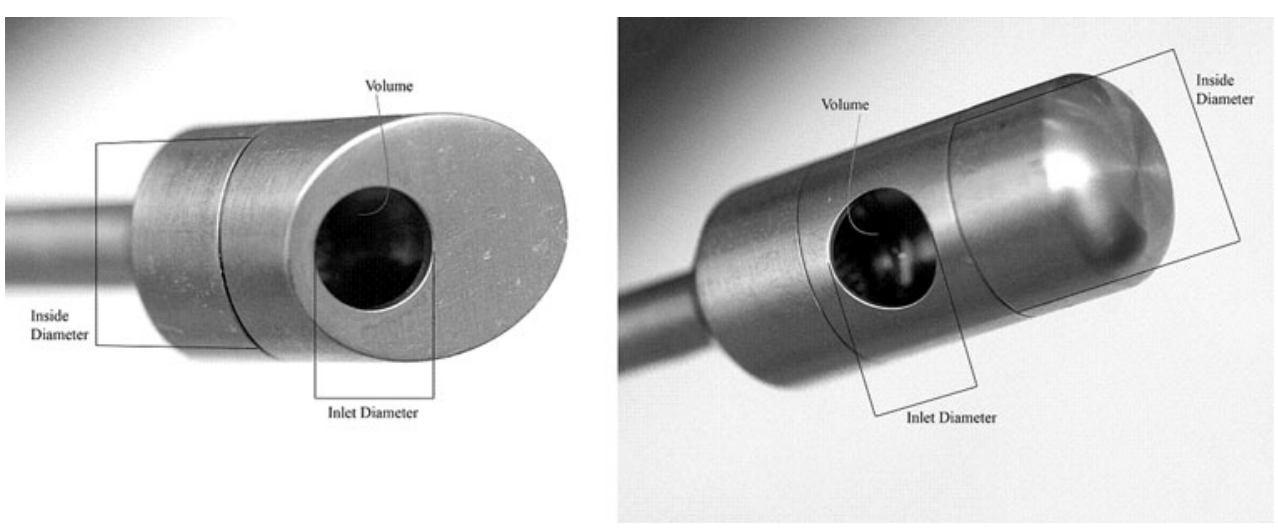

Fig. 2 Schematic views of prototypes A (left) and $\mathrm{B}$ (right)
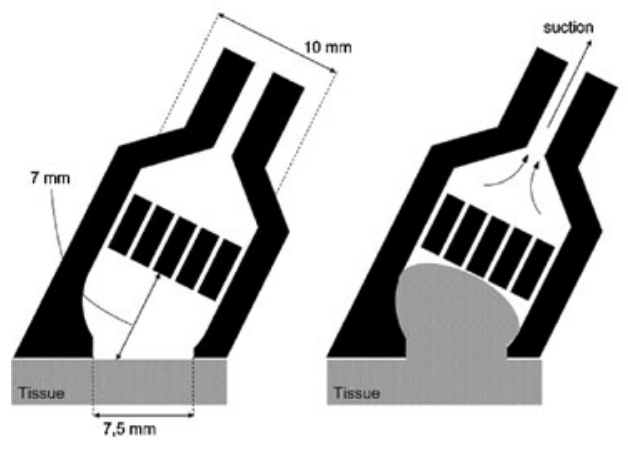

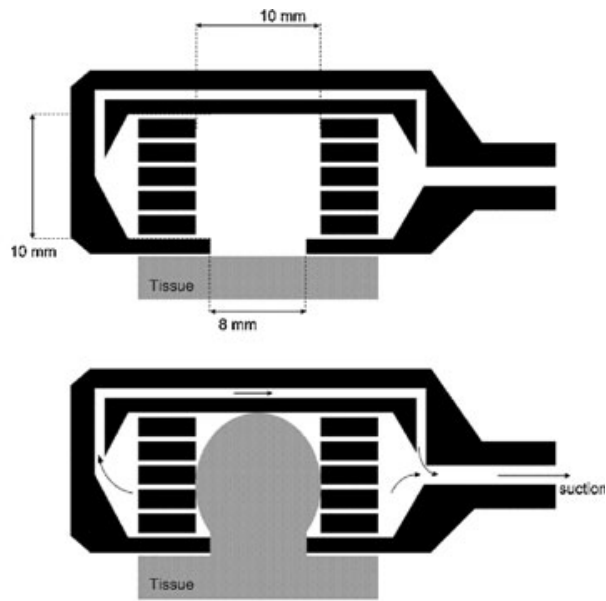

vacuum level (60 $\mathrm{kPa}$ or $20 \mathrm{kPa}$, in which $100 \mathrm{kPa}$ was the atmosphere and $0 \mathrm{kPa}$ was the absolute minimum) measured by a vacuum transducer (Econtronic, Germany) and a calibrated vacuum reader with digital output (100-0 kPa).

Both prototypes had two control options: grasping tissue and releasing tissue. To grasp tissue, the nozzle of the prototype was placed on the tissue surface, and the opening of the shaft was closed of by means of a finger. The tissue was sucked into the nozzle. The nozzle of prototype A had an inlet diameter of $7.5 \mathrm{~mm}$ and a grasp volume of $0.66 \mathrm{ml}$. The nozzle of prototype B had an inlet diameter of $8 \mathrm{~mm}$ and a grasp volume of $1.33 \mathrm{ml}$. Prototype A used a one-way suction system, and prototype B used a two-way suction system (Fig. 2). The suction systems determined the outer shape of both nozzles. The angle of the chamfered tip of prototype A was arbitrarily chosen, so the chamfer had no intentional function. Both nozzles used strainers to prevent the tissue from bulging into the instrument. To release the grasped tissue, the finger was lifted from the opening on the shaft to create a leak, which decreased the vacuum level, causing the tissue to slip out of the nozzle.

During laparoscopic procedures, segments of the bowel often need to be moved and repositioned. Such manipulations required a firm grip on the delicate bowel. Two simple manipulations were performed for both prototypes by two experienced surgeons to simulate such manipulations. For the first manipulation, the tissue was grasped and lifted $90^{\circ}$ upward $15 \mathrm{~cm}$ (Fig. 3). For the second manipulation, the tissue was grasped and pulled horizontally $20 \mathrm{~cm}$ (Figs. 4 and 5). Each manipulation was repeated 20 times for each prototype at a vacuum level of $60 \mathrm{kPa}$ and 20 times for each prototype at a vacuum level of $20 \mathrm{kPa}$. A total of 160 manipulations were assessed. In addition, the bowel was grasped at a level of $20 \mathrm{kPa}$ for $60 \mathrm{~s}$, once for each prototype.

All effects of the manipulations were macroscopically assessed by two experienced surgeons in terms of tissue damage. Both surgeons examined the small bowel 15 min after the assessment of the 160 manipulations for tissue damage as a final checkup. The tissue damages were categorized into five levels of visible damage: (1) no damage at all, (2) bruise or ecchymoses (tissue layers intact), (3) serosa damage, (4) seromuscular damage, and (5) perforation of the bowel.

As an additional test, the liver and the spleen were lifted $90^{\circ}$ upward $10 \mathrm{~cm}$, and the gallbladder was grasped and elevated. All manipulations during this test were repeated 10 times at a vacuum level of $20 \mathrm{kPa}$. Prototype B was 


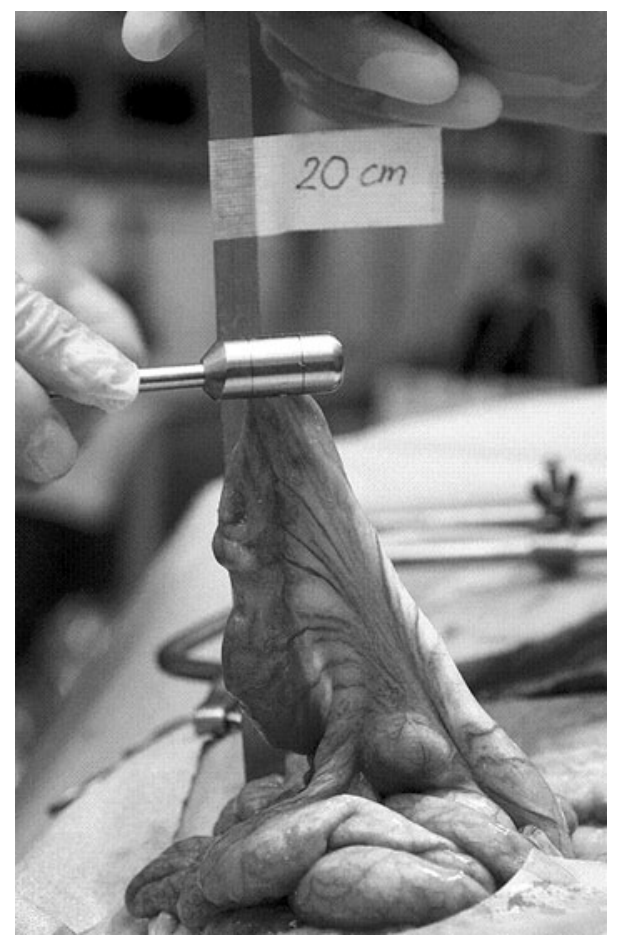

Fig. 3 Lifting of the bowel upward

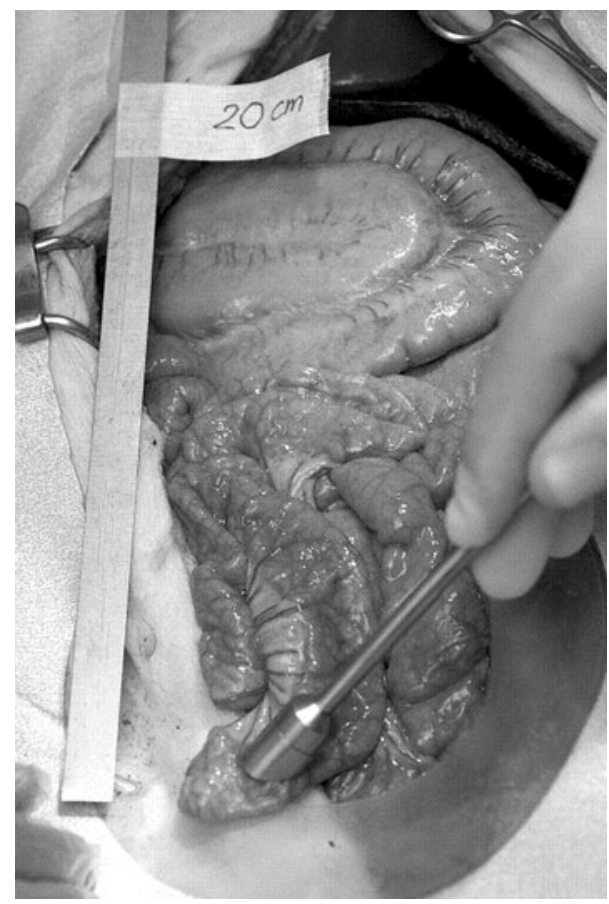

Fig. 4 Pulling of the bowel sideways (start)

used for these additional tests. Tissue damage involving the liver, the spleen, and the gallbladder also was assessed macroscopically and described.

All bowel manipulations were assessed for successful and unsuccessful grasping. Grasping was considered

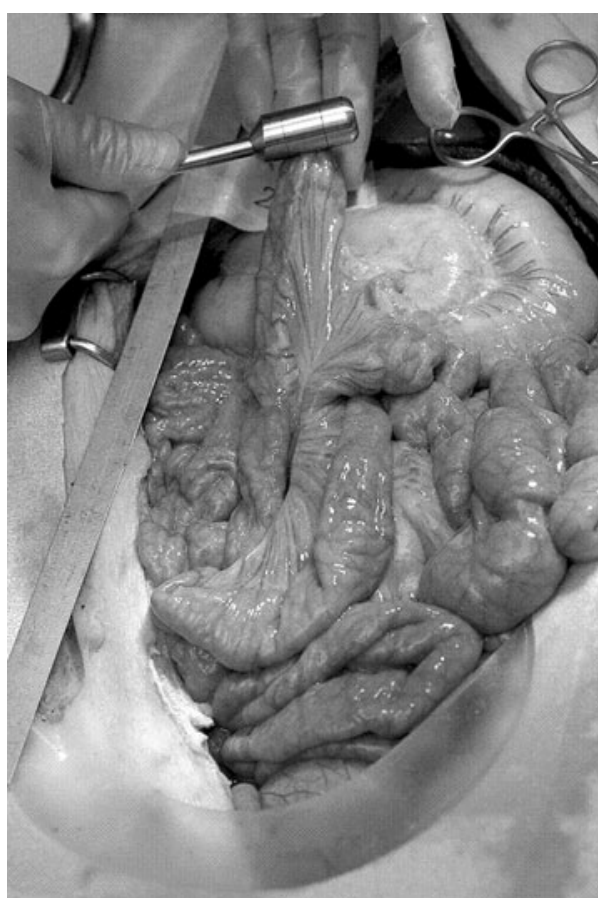

Fig. 5 Pulling of the bowel sideways (end)

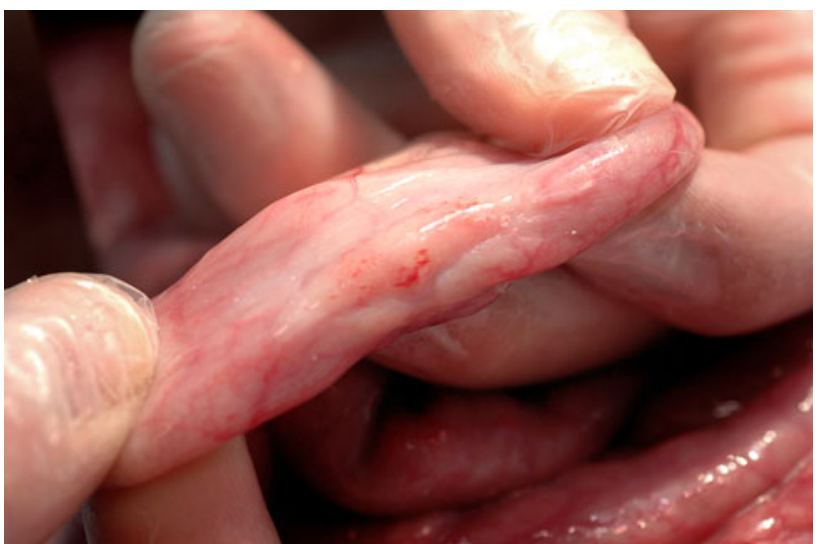

Fig. 6 Ecchymosis example 1

successful when the tissue was grasped instantly and lifted or pulled up the prescribed distance before it was released. Deviations from this definition were assessed as unsuccessful. Both prototypes grasped the tissue in a rather complex manner due to deformation of the tissue as it bulged into the nozzle (Figs. 1 and 2).

The tension and stresses exerted on the tissue could not be determined with the available data. Therefore, no comparison with existing laparoscopic graspers could be made in terms of these aspects.

For the experiments, an anesthetized healthy female pig weighing $34 \mathrm{~kg}$ was used. The experiment took place in the department of experimental surgery at the Amsterdam Medical Center. 


\section{Results}

The results with regard to tissue damage at both vacuum levels, 60 and $20 \mathrm{kPa}$, and for both prototypes are shown in Table 1 . When the grasped bowel tissue was lifted $90^{\circ}$ upward $15 \mathrm{~cm}, 14$ small ecchymoses were observed (from 40 manipulations assessed) at a vacuum level of $60 \mathrm{kPa}$. In two cases, the manipulations were unsuccessful. Both unsuccessful manipulations were performed with prototype $\mathrm{B}$.

At a vacuum level of $20 \mathrm{kPa}, 24$ small ecchymoses (examples shown in Figs. 6 and 7) were observed (from 40 manipulations assessed). In one case, the manipulation was unsuccessful. The unsuccessful manipulation was performed with prototype A.

When the grasped bowel was pulled horizontally for $20 \mathrm{~cm}$ at a vacuum level of $60 \mathrm{kPa}, 7$ small ecchymoses were observed (from 40 manipulations assessed). In one case, the manipulation was unsuccessful. The unsuccessful manipulation was performed with prototype A.

When the grasped bowel tissue was pulled horizontally for $20 \mathrm{~cm}$ at a vacuum level of $20 \mathrm{kPa}, 18$ small ecchymoses were observed (from 40 manipulations assessed). No damages occurred with either prototype during the unsuccessful manipulations. The unsuccessful manipulation at a vacuum level of $20 \mathrm{kPa}$ was caused by an inaccuracy of one of the surgeons. The manipulation started before the tissue was properly sucked into the nozzle. The unsuccessful manipulation at a vacuum level of $60 \mathrm{kPa}$ was caused by leakage due to tissue variations, lack of grip, or both.

No noticeable difference in tissue damage between the two prototypes (A and B) was observed. With prototype B, the bowel was not automatically released at either vacuum

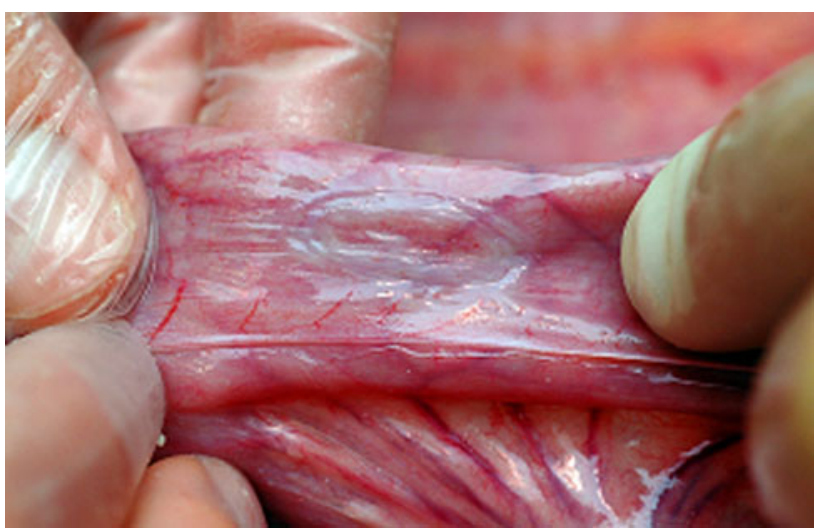

Fig. 7 Ecchymosis example 2

level when the surgeon lifted his finger from the opening on the shaft. With both prototypes, it was easier to release the tissue at a vacuum level of $60 \mathrm{kPa}$ than at a vacuum level of $20 \mathrm{kPa}$. This seemed normal because the vacuum forces were lower at a lower vacuum level.

A number of times, the opening of the nozzle caused an imprint on the tissue surface. The serosa was still intact, and the imprint disappeared after a few minutes. In addition to the experiments conducted, the tissue was grasped with a vacuum level of $20 \mathrm{kPa}$ for $60 \mathrm{~s}$, once for each prototype. The tissue was assessed in both cases by both surgeons. The ecchymoses caused by the vacuum forces disappeared after a few minutes.

With regard to liver, spleen, and gallbladder tissue damage at a vacuum level of $20 \mathrm{kPa}$ with prototype $\mathrm{B}$, the results can be described as follows. The manipulations on the liver resulted in no visible tissue damage, and after $10 \mathrm{~min}$, the nozzle prints on the surface of the liver caused
Table 1 Results of the observations regarding tissue damage at vacuum levels 60 and $20 \mathrm{kPa}$

\begin{tabular}{lccc}
\hline & Upward $(n)$ & Sideways $(n)$ & Total $(n)$ \\
\hline $60 \mathrm{kPa}$ & & & \\
Manipulations & 40 & 40 & 80 \\
Successful manipulations, no damage & 26 & 33 & 59 \\
Successful manipulations, nonconsequential damage & 14 & 7 & 21 \\
Successful manipulations, consequential damage & 0 & 0 & 0 \\
Unsuccessful manipulations, no damage & 2 & 1 & 3 \\
Unsuccessful manipulations, nonconsequential damage & 0 & 0 & 0 \\
Unsuccessful manipulations, consequential damage & 0 & 0 & 0 \\
20 kPa & & & 80 \\
Manipulations & 40 & 40 & 38 \\
Successful manipulations, no damage & 16 & 22 & 42 \\
Successful manipulations, nonconsequential damage & 24 & 18 & 0 \\
Successful manipulations, consequential damage & 0 & 0 & 1 \\
Unsuccessful manipulations, no damage & 1 & 0 & 0 \\
Unsuccessful manipulations, nonconsequential damage & 0 & 0 & 0 \\
Unsuccessful manipulations, consequential damage & 0 & 0 & \\
\hline
\end{tabular}


by the nozzle disappeared. The manipulations on the spleen also resulted in no visible tissue damage, but the nozzle prints remained visible after $10 \mathrm{~min}$. Finally, the manipulations on the gallbladder, as on the liver and spleen, resulted in no visible tissue damage.

\section{Discussion}

The physical principles of the vacuum prototypes allowed pig bowel tissue to be grasped safely, up to a vacuum level of $20 \mathrm{kPa}$. From the total of 160 manipulations, 63 ecchymoses were observed and classified as not relevant and negligible. No torn tissue layers or tissue perforations were observed. The surgeons agreed in their assessments for more than $99 \%$ of all the manipulations.

Ecchymoses and serosa damage are considered nonconsequential. These types of damages have no consequences whatsoever. Seromuscular damage is considered potentially consequential and may lead to consequential damage including perforation of the bowel, adhesions, and scars.

In our study, the small bowel was as healthy before as after the final checkup 15 min after the primary assessment. Pig bowel tissue was used for the experiments. The use of pig bowel tissue for testing of the vacuum grasper was justified because the strength of pig bowel tissue is approximately comparable with that of human bowel tissue [7].

A vacuum instrument has a number of interesting characteristics with regard to handling of the bowel. These characteristics lie within the physical principles of a vacuum instrument and can be described as follows. When tissue is grasped firmly by means of the tested prototypes, the inlet diameter (Figs. 1 and 2) of the nozzle is sealed of by the tissue. A vacuum instrument therefore automatically uses its entire surface area to grasp and hold the tissue. The forces applied to the grasped tissue remain practically constant and can be preset at a safe level.

The vacuum level inside the nozzle is closed off from the outside atmosphere by means of the grasped tissue. When a leak occurs, the outside atmosphere starts to level with the vacuum level inside the nozzle. This causes the vacuum forces (grasp forces) to decrease, and hence, the tissue starts to slip. To conclude, the likelihood of tissue damage due to slip is minimal because the forces applied to the tissue become minimal.

A vacuum instrument seems less sensitive to variations within tissue. It is presumed that because the tissue is not compressed for it to be firmly grasped, a vacuum instrument is less sensitive to variations in wall thickness, tissue folds, and bowel mesentery. It also is presumed that vascularization of the tissue is less compromised by a vacuum instrument. The fact that during the experiment no relevant damages were observed and four of the 160 manipulations were assessed as unsuccessful underscore this presumption.

The nozzle has no moving parts controlled by the user. The forces that grasp and hold the tissue are determined by the level of vacuum, preset at a constant level independently of the surgeon. Therefore, when using a vacuum instrument, a novice surgeon applies the same forces to grasp and hold the tissue as an expert surgeon, which adds to patient safety during surgical procedures.

The main causes of unsuccessful grasping are exerted vacuum forces insufficiently strong to provide a firm grip, inaccuracy of the user such as moving the tissue before it is properly grasped, and leakage between the nozzle and the grasped tissue due to variations within the tissue such as wall thickness and tissue folds.

In addition to the tests conducted on pig bowel tissue, a number of manipulations were performed on the liver, the spleen, and the gallbladder. Prototype B was used for these additional tests. The manipulations on all three types of tissue resulted in no visible organ damages. These tests indicate that a vacuum instrument can be used to grasp the spleen, the liver or the gallbladder without causing damage to these types of tissue. Other studies regarding laparoscopic splenectomy [25] and laparoscopic adrenalectomy [26] underscore this finding.

Vacuum instruments, such as the tested prototypes, have the potential to be used as grasper instruments in minimally invasive surgery. The question rises whether a vacuum instrument can be used to stabilize tissue held for longer periods. Ongoing further tests are being conducted to evaluate the use of a vacuum instrument in relation to soft tissue characteristics. It also is noted that when leakage occurs, the continuous suction flow of the vacuum pump compromises the aero-peritoneum if the prototypes are to be used in a laparoscopic setting.

A manually operated vacuum instrument may solve this potential problem. Compared with the aero-peritoneum, a manually operated vacuum instrument uses a very small volume to generate the vacuum (grasp forces). A manually generated vacuum also is noncontinuous, which means that air leakage is not bypassed as when a vacuum pump is used. For conventional mechanical grasping, the user manually generates the grasp forces. Therefore, for a fair comparative test between vacuum grasping and conventional mechanical grasping in a laparoscopic setting, manually operated vacuum instruments (prototypes) must be developed. Further tests are being conducted to evaluate both vacuum grasping (manually) and mechanical grasping. 
Acknowledgments The department of experimental surgery at the Amsterdam Medical Center is acknowledged for assistance and expertise with regard to the experiments conducted.

Disclosures D. Vonck received funding from the Delft University of Technology. R. H. M. Goossens, D. J. van Eijk, I, H. J. T. de Hingh, and J. J. Jakimowicz have no conflicts of interest or financial ties to disclose.

Open Access This article is distributed under the terms of the Creative Commons Attribution Noncommercial License which permits any noncommercial use, distribution, and reproduction in any medium, provided the original author(s) and source are credited.

\section{References}

1. de Visser H (2003) Grasping safely, instruments for bowel manipulation investigated. Thesis, Delft University of Technology, Delft, The Netherlands, ISBN 90-407-2421-0

2. Marucci DD, Cartmill JA, Walsh WR, Martin CJ (2000) Patterns of failure at the instrument-tissue interface. J Surg Res 93:16-20

3. Shakeshaft AJ, Cartmill JA, Walsh WR, Martin CJ (2001) A curved edge moderates high pressure generated by a laparoscopic grasper. Surg Endosc 15:1232-1234

4. Bannenberg JJG, Hoebe Ch, Sjoerdsma W, Meijer DW, Klopper PJ (1994) Tissue damage by atraumatic bowel clamps (abstract). Min Invas Ther 3(Suppl 1):37

5. Cartmill JA, Shakshaft AJ, Walsh WR, Martin CJ (1999) High pressures are generated at the tip of laparoscopic graspers. Aust $\mathrm{N}$ Z J Surg 69:127-130

6. Frank TG, Cuschieri A (1997) Prehensile atraumatic grasper with intuitive ergonomics. Surg Endosc 11:1036-1039

7. Heijnsdijk EAM (2004) Tissue manipulation in laparoscopic surgery. Thesis, Delft University of Technology, Delft, The Netherlands, ISBN 90-6464-779-8

8. Sjoerdsma W, Herder JL, Horward MJ, Jansen A, Bannenberg JJG, Grimbergen CA (1997) Force transmission of laparoscopic instruments. Minim Invasive Ther Allied Technol 6:274-278

9. Rosen J, Hannaford B, MacFarlane MP, Sinanan MN (1999) Force controlled and teleoperated endoscopic grasper for minimally invasive surgery experimental performance evaluation. IEEE Trans Biomed Eng 46:1212-1221

10. Rosen J, Hannaford B, Richards CG, Sinanan MN (2001) Markov modeling of minimally invasive surgery based on tool/tissue interaction and force/torque signatures for evaluating surgical skills. IEEE Trans Biomed Eng 48:579-591

11. Westebring-van der Putten EP, Goossens RHM, Jakimowicz JJ, Dankelman J (2008) Haptic perception in minimally invasive surgery: a review. Minim Invasive Ther Allied Technol 17:3-16
12. den Boer KT, Herder JL, Sjoerdsma W, Meijer DW, Gouma DJ, Stassen HG (1999) Sensitivity of laparoscopic dissectors: what can you feel? Surg Endosc 13:869-873

13. Trejo A, Jung MC, Oleynikov D, Hallbeck MS (2007) Effect of handle design and target location on insertion and aim with a laparoscopic surgical tool. Appl Ergon 38:745-753

14. Manukyan GA, Waseda M, Inaki N, Torres Bermudez JR, Gacek IA, Rudinski A, Buess GF (2007) Ergonomics with the use of curved versus straight laparoscopic graspers during rectosigmoid resection: results of a multiprofile comparative study. Surg Endosc 21:1079-1089

15. Hu T, Tholey G, Desai JP, Castellanos AE (2004) Evaluation of a laparoscopic grasper with force feedback. Surg Endosc 18:863867

16. Marucci DD, Shakeshaft AJ, Cartmill JA, Cox MR, Adams SG, Martin CJ (2000) Grasper trauma during laparoscopic cholecystectomy. Aust N Z J Surg 70:578-581

17. van Veelen MA (2003) Human-product interaction in minimally invasive surgery: a design vision for innovative products. Thesis, Delft University of Technology, Delft, the Netherlands, ISBN 909016655-6

18. Voort van der M, Heijnsdijk EAM, Douma DJ (2004) A review of bowel injury as a complication of laparoscopy. Br J Surg 10:1253-1258

19. Taylor AM, Li MK (1994) Laparoscopic management of complications following laparoscopic cholecystectomy. Aust N Z J Surg 64:827-829

20. Deziel DJ, Millikan KW, Econumou SG, Doolas A, Ko ST, Airan MC (1993) Complications of laparoscopic cholecystectomy: a national survey of 4, 292 hospitals and an analysis of 77,604 cases. Am J Surg 165:9-14

21. Reich H (1992) Laparoscopic bowel injury. Surg Laparosc Endosc 2:74-78

22. Schafer M, Lauper M, Krahenbuhl L (2001) Trocar and Veress needle injuries during laparoscopy. Surg Endosc 15:275-280

23. Croce E, Golia M, Russo R, Azzola M, Olmi S, De Murtas G (1999) Duodenal perforations after laparoscopic cholecystectomy. Surg Endosc 13:523-525

24. Sun SS, Li JY, Hu PY, Wu SJ (2005) Starfish-assisted off-pump obliteration of massive coronary arteriovenous fistulae. Tex Heart Ins J 32:595-597

25. Gentilli S, Velardocchia M, Ferrero A, Martelli S, Donadio F (1998) Laparoscopic splenectomy: how to make it easier using an innovative atraumatic suction grasper. Surg Endosc 12:13451347

26. Gentilli S, Ferrero A, Velardocchia M, Garavoglia M (1998) Laparoscopic adrenalectomy: advantages of an atraumatic suction grasper. Surg Laparosc Endosc 8:335-337

27. Udwadia TE, Kathrani BK, Bernie W, Gadgil US, Chariar VM (2005) Vacuum-assisted abdominal wall lift for minimal access surgery: a porcine model study. Surg Endosc 19:1113-1119 